This document is the accepted manuscript version of the following article:

Zabilskiy, M., Sushkevich, V. L., Newton, M. A., \& van Bokhoven, J. A. (2020). Copper-zinc alloy-free synthesis of methanol from carbon dioxide over Cu/Zno/Faujasite. ACS Catalysis, $10(X X X), 14240-14244$. https://doi.org/10.1021/acscata1.0c03661

\title{
Copper-Zinc Alloy-Free Synthesis of Methanol from Carbon Dioxide over Cu/ZnO/Faujasite
}

\author{
Maxim Zabilskiy, ${ }^{\mathrm{a}, *}$ Vitaly L. Sushkevich, ${ }^{\mathrm{a}}$ Mark A. Newton ${ }^{\mathrm{b}}$ and Jeroen A. van Bokhoven ${ }^{\mathrm{a}, \mathrm{b}, *}$ \\ aLaboratory for Catalysis and Sustainable Chemistry, Paul Scherrer Institute, 5232 Villigen PSI (Switzerland) \\ bInstitute for Chemistry and Bioengineering, ETH Zurich, Vladimir-Prelog-Weg 1, 8o93 Zürich (Switzerland) \\ ${ }^{*}$ Corresponding authors: \\ E-mail address: maxim.zabilskiy@psi.ch (M. Zabilskiy) \\ E-mail address: jeroen.vanbokhoven@chem.ethz.ch (J.A. van Bokhoven)
}

\begin{abstract}
The mechanism of carbon dioxide hydrogenation to methanol over Cu/ZnO materials has been explored for decades, however, the question of the active site still remains open to discussion. We used operando time resolved XAS and timeresolved isotope labeling experiments coupled with FTIR spectroscopy and MS analysis to elucidate the reaction mechanism and study the active sites and intermediates over a $\mathrm{Cu} / \mathrm{ZnO}$ catalyst in the course of carbon dioxide conversion to methanol. No reduction of the zinc oxide, or formation of copper-zinc alloy were observed even under highly reducing conditions (15 bar of hydrogen, $260^{\circ} \mathrm{C}$ ), which leads to the conclusion that a copper zinc alloy phase is not required for high methanol yields and selectivity to be obtained. We attribute the reactive superiority of copper-zinc based system to the interplay between copper and zinc oxide phases. Our synthesis protocol provides a way to produce this copper zinc oxide interface, without having to go through an alloy phase.
\end{abstract}

KEYWORDS: $\mathrm{CO}_{2}$ hydrogenation, methanol, $\mathrm{CuZn}$ alloy, operando XAS, $\mathrm{Cu} / \mathrm{ZnO}$ catalyst, isotope-labelling experiment.

The valorization of carbon dioxide through conversion into methanol has long been considered as a promising process. ${ }^{1}$ Not only might such a process help to decrease anthropogenic greenhouse effects of carbon dioxide upon the environment, but methanol itself is a valuable product which can be used either as a liquid fuel additive, or as a precursor to value-added chemicals. ${ }^{2-4}$ In spite of extensive efforts from both industry and academia, however, industrial application of this process has yet to become a reality. . $^{-7}$

$\mathrm{Cu} / \mathrm{ZnO}$ based catalysts currently possess the highest activity for catalytic carbon dioxide hydrogenation to methanol. ${ }^{8}$ To further improve this catalytic system an understanding of the reaction mechanism and the structure of the active sites is vital for achieving the highest carbon dioxide conversion and methanol selectivity. Despite numerous extensive studies over past decades, however, the nature of active sites and reaction pathways of this process over $\mathrm{Cu} / \mathrm{ZnO}$ systems remains the subject of intense debate..$^{-17}$

The mechanistic concept, which attributes activity in this reaction to the formation of a surface copper-zinc alloy, has dominated this discussion for some time. Numerous works have claimed that surface copper-zinc alloys at low zinc coverages $\left(\theta_{\mathrm{Zn}} \leq 0.15\right.$ monolayers) are stable under reaction conditions and responsible for methanol synthesis. Recently, however, Kattel et al. ${ }^{15}$ have shown by X-ray photoemission spectroscopy (XPS) that copper-zinc alloy, even at low zinc coverage, undergoes oxidation and that copper-zinc oxide interfacial sites are the active species for methanol synthesis from carbon dioxide. This observation has caused a new round of debate. ${ }^{6,17}$ We believe that, at least in part, the reasons for such discrepancies originate from carrying out experiments under widely varying experimental conditions that deviate significantly from those required ( $240 \leq \mathrm{T} \leq 280^{\circ} \mathrm{C}$ and $\mathrm{P} \geq 15$ bar) in the catalytic process. Our recent operando study of the $\mathrm{Cu} / \mathrm{ZnO} / \mathrm{Al}_{2} \mathrm{O}_{3}$ industrial catalyst at 15 bars and $220-280{ }^{\circ} \mathrm{C}$ has shown that the copper-zinc alloy does indeed undergo oxidation in the presence of carbon dioxide and as such can be considered only as possible precursor to the genuine active sites. ${ }^{18}$

In this study, we perform a mechanistic investigation of carbon dioxide hydrogenation to methanol over a copperzinc alloy-free catalyst comprised of metallic copper and zinc oxide phases supported on zeolite faujasite $(\mathrm{Cu} / \mathrm{ZnO} / \mathrm{FAU})$ under process-relevant catalytic conditions. By using operando time-resolved X-ray absorption spectroscopy (XAS), and high-pressure steady-state isotope labeling experiments coupled with infrared spectroscopy, we have found no spectroscopic evidence of the existence of copper-zinc alloy or its participation in the reaction mechanism. 
$\mathrm{Cu} / \mathrm{ZnO} / \mathrm{FAU}$, containing $2.6 \mathrm{wt}$ \% of copper and $2.4 \mathrm{wt}$. $\%$ of zinc, was prepared through ion-exchange of commercial zeolite faujasite $\left(\mathrm{SiO}_{2} / \mathrm{Al}_{2} \mathrm{O}_{3}=12\right)$ followed by the precipitation of basic copper and zinc carbonates in the zeolite pores using o.1 M sodium carbonate. By using this method, separate copper and zinc oxide phases with high dispersions are initially formed inside the zeolite pores (Figures $\mathrm{S}_{1}-\mathrm{S}_{3}$ ). Figure 1 shows the results of catalytic carbon dioxide hydrogenation over this material in a continuous flow fixed bed reactor between $240{ }^{\circ} \mathrm{C}$ and $260{ }^{\circ} \mathrm{C}$ and 30 bar. TEM investigation of the spent catalyst (Figures $\mathrm{S}_{4}-\mathrm{S}_{5}$ ) revealed partial extrusion of copper- and zinc-containing phases to the external surface of the zeolite.

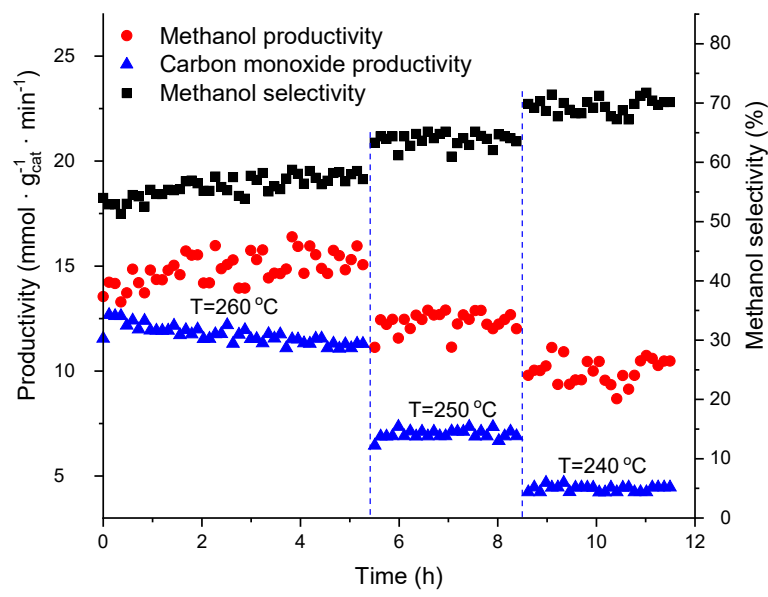

Figure 1. Results of catalytic carbon dioxide hydrogenation over $\mathrm{Cu} / \mathrm{ZnO} / \mathrm{FAU}$ catalyst in the temperature range of $240-$ $260^{\circ} \mathrm{C}$ and pressure 30 bar.

Operando IR spectroscopy was used to identify the nature of the surface species formed during carbon dioxide hydrogenation. Introduction of the reaction feed leads to the appearance of several bands at 1661,1608 and $1383 \mathrm{~cm}^{-1}$ (Figure S6). The first two bands are ascribed to asymmetric stretching vibrations of adsorbed formate species, whilst that at $1383 \mathrm{~cm}^{-1}$ arise from symmetric stretches of this species. $^{19-23}$ The presence of the two higher frequency bands points to the presence of at least two types of formate species, with the band at $1661 \mathrm{~cm}^{-1}$ assigned to the asymmetric bending of monodentate formate, while the band at 1608 $\mathrm{cm}^{-1}$ corresponds to the same vibration arising from a bidentate formate species. ${ }^{24,25}$ With increasing pressure, a new band at $1470 \mathrm{~cm}^{-1}$, attributed to bending vibrations of methoxy species, develops. Notably, no spectroscopic signatures of carbonate species were observed.

To access the structure and kinetic behavior of the intermediates formed during the hydrogenation of carbon dioxide, a steady-state transient ${ }^{12} \mathrm{CO}_{2} /{ }^{13} \mathrm{CO}_{2}$ isotope switch monitored by FTIR and mass-spectrometry (MS) was performed (Figure $2 \mathrm{a}$ ). Figure $2 \mathrm{~b}$ shows the normalized responses of the main reaction products and reagents, following a switch from a mixture of ${ }^{12} \mathrm{CO}_{2} / \mathrm{H}_{2}$ to one of ${ }^{13} \mathrm{CO}_{2} / \mathrm{H}_{2}$, with respect to inert tracer (argon). Immediately after switching, the signal due to ${ }^{12} \mathrm{CO}_{2}$ decreases together with the tracer signal, indicating a residence time of close to zero. This strongly suggests that the first step in carbon dioxide activation is irreversible and, does not proceed through the formation of strongly bound species such as carbonates; a proposition confirmed by FTIR (Figure S6). In contrast, the MS responses of two main products, carbon monoxide and methanol, show significant delay with respect to argon. This indicates that methanol formation occurs via several steps subsequent to the initial activation of carbon dioxide (Figure $\mathrm{S}_{7}$ ), as well as possible re-adsorption effects for methanol as it travels through the catalyst bed.
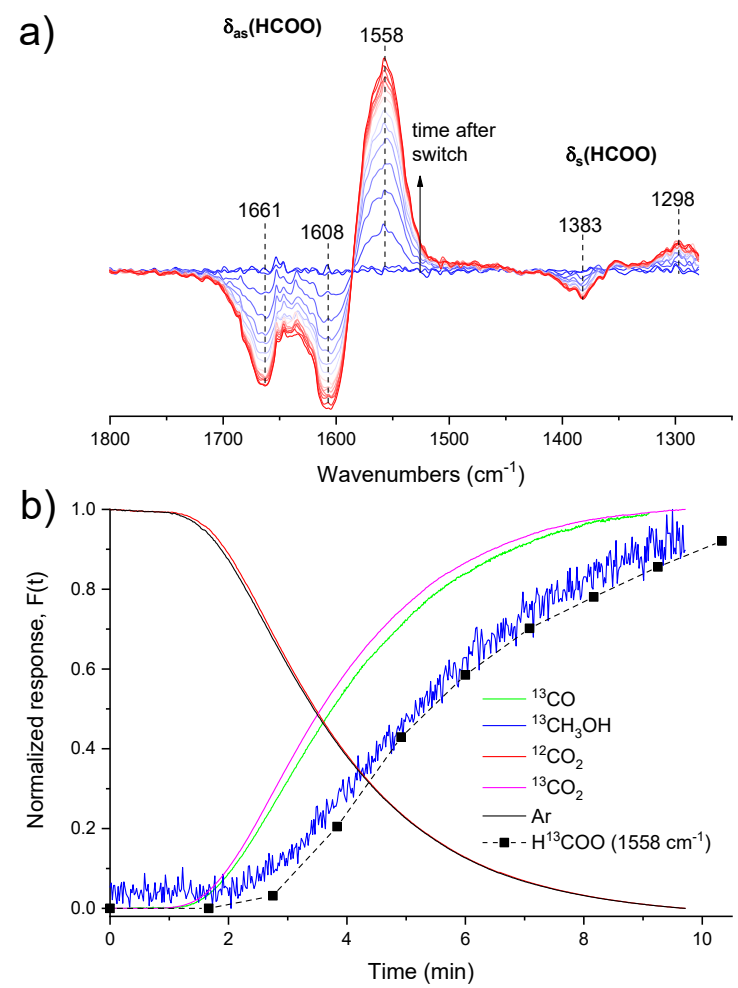

Figure 2. a) in situ FTIR difference spectra collected during transient isotope switch from ${ }^{12} \mathrm{CO}_{2} / \mathrm{H}_{2}$ to ${ }^{13} \mathrm{CO}_{2} / \mathrm{H}_{2}$ mixture over $\mathrm{Cu} / \mathrm{ZnO} / \mathrm{FAU}$ catalyst at $260{ }^{\circ} \mathrm{C}$ and 15 bar; b) Normalized MS and IR transient responses following ${ }^{12} \mathrm{CO}_{2} / \mathrm{H}_{2}$ to ${ }_{13} \mathrm{CO}_{2} / \mathrm{H}_{2}$ isotope switch over $\mathrm{Cu} / \mathrm{ZnO} / \mathrm{FAU}$ catalyst at $260{ }^{\circ} \mathrm{C}$ and 15 bar.

To access the reactivity of formate and methoxy intermediates, we followed the dynamics of these surface species during the isotope switch. Figure za shows difference time-resolved infrared spectra acquired after the switch from the mixture of ${ }^{12} \mathrm{CO}_{2} / \mathrm{H}_{2}$ to one of ${ }^{13} \mathrm{CO}_{2} / \mathrm{H}_{2}$. After the switch, the intensity of all bands corresponding to unlabeled formate species decreases, as they are simultaneously replaced by the bands at 1558 and $1298 \mathrm{~cm}^{-1}$ (see Figure 2a, Figure S8 and supplementary discussion). These bands are due to the ${ }^{13} \mathrm{C}$-labeled formate species formed from the ${ }^{13} \mathrm{CO}_{2}$ now present in the reaction feed. Importantly, after $\sim 15$ mins of reaction, full and reversible interconversion of unlabeled formate species into ${ }^{13} \mathrm{C}$-labeled ones is observed. This behavior confirms the participation of both monodentate and bidentate formate species in the reaction mechanism. Notably, no isotope exchange was observed for the methoxy species (Figure $2 \mathrm{a}$ and Figure 
S8). This points to the high stability of methoxy species on the catalyst surface and that, once formed, they do not participate in any consecutive reaction. Integration of the relative intensity of the IR bands corresponding to formates allows a comparison of their kinetic behavior with that observed for reaction products concurrently detected by mass spectrometry (Figure $2 \mathrm{~b}$ ). The normalized and zerotime corrected formate response follows precisely that due to the evolution of methanol, and therefore confirms that formate species are the reactive intermediates that lead directly to methanol.

$\mathrm{Cu}$ K-edge XANES and EXAFS spectra (Figures S9-Sio, Table $\mathrm{S}_{1}$ ), show that the copper(II) cations initially present in the zeolite undergo complete reduction to yield metallic copper nanoparticles on the surface of the catalyst during activation in hydrogen (Figure $\mathrm{S} 9$ and associated discussion). Data from transient experiments, analogous to those already presented for time-resolved isotope labeling experiment and based on cycling of the feed gas composition between $\mathrm{CO}_{2} / \mathrm{H}_{2}$ mixture and hydrogen, show that copper remains predominantly present as a nanoparticulate metallic copper phase and does not undergo any significant change (Figure S11).

In contrast, the Zn K-edge XANES of the catalyst activated in hydrogen undergoes changes at 9662.8, 9666.3 and $9672.1 \mathrm{eV}$ during these transient experiments (Figure 3a). Importantly, no evidence for the presence of reduced zinc in the form of copper zinc alloy (pre-edge at $9659 \mathrm{eV}$, Figure S12), either in the activated sample, or during operando carbon dioxide hydrogenation, was observed.

The difference XANES spectra (Figure $3 \mathrm{a}$ and Figure $\mathrm{S}_{3}$ ) indicate that the main changes after the switch from hydrogen to $\mathrm{CO}_{2} / \mathrm{H}_{2}$ mixture occurs in the region with maximum at $9666.3 \mathrm{eV}$. At the same time, the main peak of zinc formate is located at $\sim 9666.8 \mathrm{eV}$ (Figure S12). The active intermediate formate species observed during time-resolved isotope labeling experiment (Figure $2 \mathrm{a}$ ) are therefore associated with the zinc during methanol synthesis. To make unambiguous assignment of the different zinc phases that are responsible for the observed changes in $\mathrm{Zn}$ K-edge XANES spectra, analysis of the EXAFS, and Principal Component Analysis (PCA) of the XANES, were undertaken (Figures $\mathrm{S}_{14}-\mathrm{S}_{16}$ and Table S2). PCA of Zn K-edge XANES spectra of $\mathrm{Cu} / \mathrm{ZnO} / \mathrm{FAU}$ upon cycling feed gas composition at $260{ }^{\circ} \mathrm{C}$ and 15 bar reveals the presence of three principal components. The major zinc component, a highly dispersed $\mathrm{Zn}^{2+}$ phase (Figure S14a), shows a nearly constant $\sim 96 \mathrm{~mol}$. \% fraction and no significant response to cycling of the feed gas composition (Figure $3 \mathrm{~b}$ ). Besides this phase, a minority wurtzite-like zinc oxide phase is detected after the catalyst pretreatment in hydrogen. If any other minority phases are present during catalytic carbon dioxide hydrogenation, their concentrations are below detection limit and we cannot determine their role in this process. After switching the feed gas from hydrogen to the $\mathrm{CO}_{2} / \mathrm{H}_{2}$ reactive mixture, this phase undergoes conversion to a zinc formate type phase; a process that is found to be completely reversible upon returning the feed to hydrogen from the reaction mixture. This is in line with work of Kattel et al., ${ }^{17}$ who also observed decomposition of formates once the $\mathrm{CO}_{2} / \mathrm{H}_{2}$ reaction mixture was removed.

a)

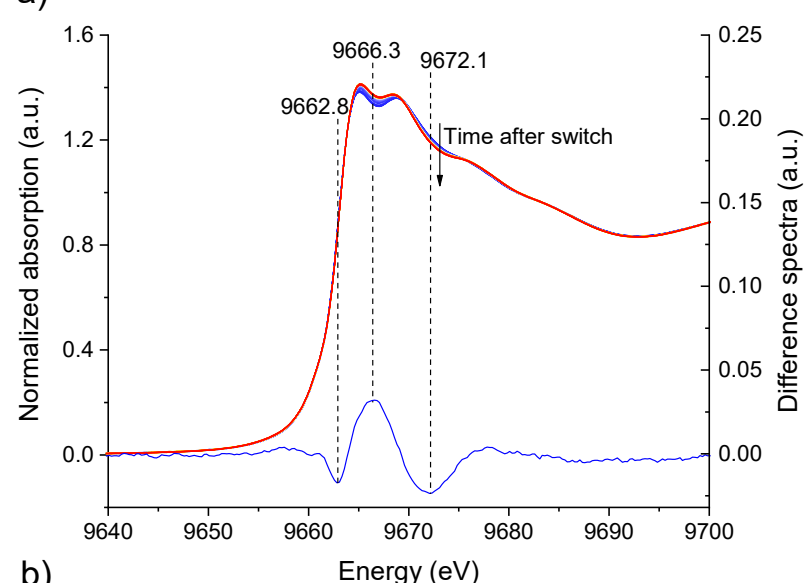

b)

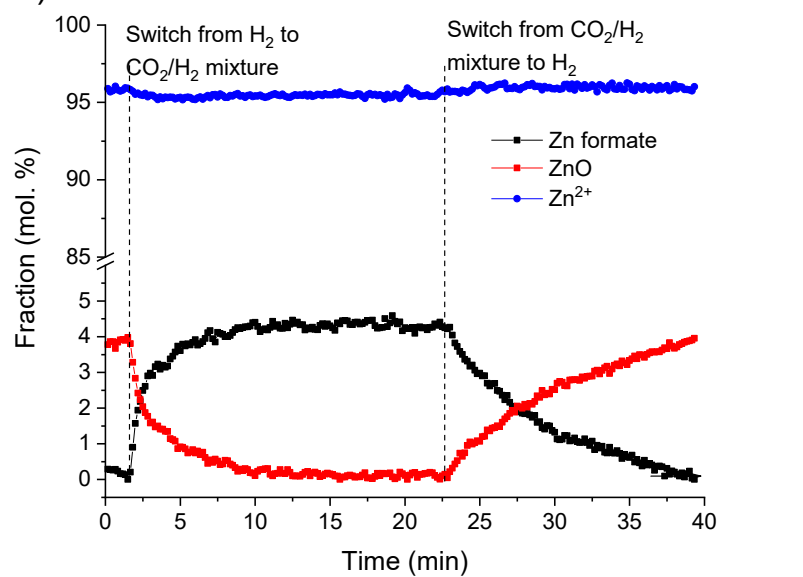

Figure 3. a) Zn K-edge XANES spectra evolution as well as difference spectrum between final and initial spectra for $\mathrm{Cu} / \mathrm{ZnO} / \mathrm{FAU}$ sample during operando switch from hydrogen to $\mathrm{CO}_{2} / \mathrm{H}_{2}$ gas reaction mixture at 15 bar and $260{ }^{\circ} \mathrm{C}$; b) The relative fractions of zinc formate, zinc oxide-wurtzite and highly dispersed $\mathrm{Zn}^{2+}$ phases determined from PCA analysis as function of time upon cycling feed gas composition at $260{ }^{\circ} \mathrm{C}$ and 15 bar.

This experiment clarifies the controversial question concerning the participation of copper-zinc alloy in the catalytic cycle of methanol synthesis from carbon dioxide. Gotti and Prins ${ }^{26}$ had, in the late 9os, questioned the finding of Nakamura et al., ${ }^{27}$ making the point that the presence of carbon dioxide and water could prevent the formation of a copper-zinc alloy. Moreover, recent publications have shown that copper-zinc alloy is unstable under carbon dioxide hydrogenation conditions and undergoes oxidation to zinc oxide or/and zinc formate. ${ }^{15,17,18}$ In the present work, the alloy phase was never observed to any measurable degree, even after the highly reductive pretreatment. Yet, the catalyst achieves significant activity and selectivity for carbon dioxide hydrogenation to methanol: the activity, normalized per mol of copper, obtained from this sample is comparable to that observed over the 
commercial $\mathrm{Cu} / \mathrm{ZnO} / \mathrm{Al}_{2} \mathrm{O}_{3}$ catalyst, which does form a copper-zinc alloy during pretreatment (Table $\mathrm{S}_{3}$ and Figure $\left.\mathrm{S}_{17}\right)$. The fact that, under hydrogen, no observable amount of alloy phase forms, suggests that under reaction conditions, and therefore in the presence of carbon dioxide and water, the formation of such a phase, even in the form of short-lived intermediates, is highly unlikely. Instead, our results suggest that activation of carbon dioxide and formation of zinc formate species occur at zinc oxide surfaces in close proximity to metallic copper nanoparticles. Furthermore, purely oxide-based systems, like $\mathrm{ZnO}, \mathrm{In}_{2} \mathrm{O}_{3}$, $\mathrm{ZnO}-\mathrm{Cr}_{2} \mathrm{O}_{3}$, and $\mathrm{ZnO}-\mathrm{ZrO}_{2}$, also convert carbon dioxide to methanol.9,28-32 This indicates that the presence of alloyed phases are not necessary to perform this reaction. However, bi-functional catalysts that contain both an oxide component, which is responsible for activation of carbon dioxide, and a metallic counterpart, which can activate and split hydrogen efficiently, show much higher catalyst activity than these oxide-only systems.

Figure 3 b shows that only a small fraction of zinc, in this case zinc oxide in a wurtzite-like form, in $\mathrm{Cu} / \mathrm{ZnO} / \mathrm{FAU}$ is active in carbon dioxide hydrogenation to methanol. The zeolite acts as a reservoir that permits the extrusion of both copper and zinc to the surface of the catalyst during reduction, where these components can achieve the intimacy of interaction required to generate the active sites required for the selective conversion of carbon dioxide. In this material copper is extruded, reduced, and then sintered to yield sizeable copper nanoparticles (see TEM and $\mathrm{Cu} \mathrm{K}$ edge EXAFS fitting in supplementary) on the outer zeolite surface. At the same time, according to Zn K-edge EXAFS fitting (Figure S16 and Table $\mathrm{S}_{2}$ and associated discussion), as well as PCA XANES analysis of activated $\mathrm{Cu} / \mathrm{ZnO} / \mathrm{FAU}$ sample (Figure 3 and Figures $\mathrm{S}_{14}-\mathrm{S}_{15}$ ), zinc oxide is more resistant to extrusion and/or sintering, and only a small fraction of zinc is transformed into a wurtzite-like zinc oxide located at the external zeolite surface. And only this phase, which is in intimate contact with the metallic copper (Figures $\mathrm{S}_{4}-\mathrm{S}_{5}$ ), is responsible for activation of carbon dioxide, yielding zinc formate species that can be hydrogenated to yield methanol (Figures 2 and $3 \mathrm{~b}$ ). At the same time, a highly dispersed $\mathrm{Zn}^{2+}$ phase located in zeolite cavities remains inactive, indicating the importance of $\mathrm{Cu} / \mathrm{ZnO}$ interplay in this catalyst.

To summarize, we have used a combination of operando time resolved XAS and steady-state ${ }^{12} \mathrm{CO}_{2} /{ }^{13} \mathrm{CO}_{2}$ isotope transient experiment coupled with infrared spectroscopy and MS analysis to monitor the reactive behavior of a $\mathrm{Cu} / \mathrm{ZnO} / \mathrm{FAU}$ catalyst under realistic reaction conditions (260 ${ }^{\circ} \mathrm{C}$ and 15 bar). Even in a pure hydrogen environment, no zinc phase is reduced and a copper zinc alloy phase does not form over $\mathrm{Cu} / \mathrm{ZnO} / \mathrm{FAU}$ : the presence of this phase is, therefore, not a prerequisite for the bifunctional $\mathrm{Cu} / \mathrm{ZnO}$ system to be an active and selective catalyst for methanol synthesis from carbon dioxide and hydrogen. Only the wurtzite-like zinc oxide, present at the surface of the zeolite crystals and in intimate contact with metallic copper nanoparticles, forms the reactive zinc formates. Our re- sults constitute a significant step in understanding the reaction mechanism and structure of active sites in copperzinc based catalysts for hydrogenation of carbon dioxide. From the methodological point of view, a combination of powerful techniques such as time-resolved X-ray and infrared spectroscopies, with isotope tracing and switch experiments provides molecular-level insight into reaction mechanisms under harsh and industrially relevant conditions.

\section{ASSOCIATED CONTENT}

Supporting Information.

The Supporting Information is available free of charge via the Internet at http://pubs.acs.org.

Preparation and characterization of $\mathrm{Cu} / \mathrm{ZnO} / \mathrm{FAU}$ material, description of operando XAS and IR experiments, TEM micrographs, additional FTIR and XAS results.

\section{AUTHOR INFORMATION}

\section{Corresponding Authors}

Maxim Zabilskiy - Laboratory for Catalysis and sustainable Chemistry, Paul Scherrer Institute, 5232 Villigen PSI, Switzerland. E-mail: maxim.zabilskiy@psi.ch

Jeroen A. van Bokhoven - Institute for Chemistry and Bioengineering, ETH Zurich, Vladimir-Prelog-Weg 1, 8093Zürich and Laboratory for Catalysis and sustainable Chemistry, Paul Scherrer Institute, 5232 Villigen PSI, Switzerland. E-mail: jeroen.vanbokhoven@chem.ethz.ch

\section{Author Contributions}

M.Z. and J.A.v.B conceived the idea for the study. V.L.S. and M.Z. designed, performed and analyzed FTIR experiments. M.Z., V.L.S. and M.A.N. designed, performed and interpreted operando XAS experiments. M.A.N. performed the EXAFS data analysis. M.Z. wrote the draft with contributions from all the other authors.

\section{Notes}

The authors declare no competing financial interest

\section{ACKNOWLEDGMENT}

We acknowledge the Swiss Light Source (SuperXAS beamline) and ESRF (Swiss-Norwegian and Dutch Belgian beamlines) for providing access to these facilities for XAS measurements. Dr. M. Nachtegaal, Dr. O. Safonova, Dr. D. Stoian, Dr. W. van Beek and Dr. A. Longo are acknowledged for local contacting during beamtimes. V.L.S. thanks the ESI platform of Paul Scherrer Institute for funding. M.A.N. acknowledge Shell Global Solutions for the partial funding of his position. We thank Dr. Frank Krumeich for performing electron microscopy at the Scientific Centre for Optical and Electron Microscopy (ScopeM) ETH Zurich.

\section{REFERENCES}

(1) Ye, R. P.; Ding, J.; Gong, W.; Argyle, M. D.; Zhong, Q.; Wang, Y.; Russell, C. K.; Xu, Z.; Russell, A. G.; Li, Q.; Fan, M.; Yao, Y. G. $\mathrm{CO}_{2}$ Hydrogenation to High-Value Products via Heterogeneous Catalysis. Nat. Commun. 2019, 10, 5698. 

M.; Gascon, J. Recent Trends and Fundamental Insights in the Methanol-to-Hydrocarbons Process. Nat. Catal. 2018, 1, 398-411.

Awad, O. I.; Mamat, R.; Ali, O. M.; Sidik, N. A. C.; Yusaf, T.; Kadirgama, K.; Kettner, M. Alcohol and Ether as Alternative Fuels in Spark Ignition Engine: A Review. Renew. Sustain. Energy Rev. 2018, 82, 2586-2605.

(4) Verhelst, S.; Turner, J. W.; Sileghem, L.; Vancoillie, J. Methanol as a Fuel for Internal Combustion Engines. Prog. Energy Combust. Sci. 2019, 70, 43-88. González-Garay, A.; Frei, M. S.; Al-Qahtani, A.; Mondelli, C.; Guillén-Gosálbez, G.; Pérez-Ramírez, J. Plant-to-Planet Analysis of $\mathrm{CO}_{2}$-Based Methanol Processes. Energy Environ. Sci. 2019, 12, 3425-3436.

(6) Hepburn, C.; Adlen, E.; Beddington, J.; Carter, E. A.; Fuss, S.; Mac Dowell, N.; Minx, J. C.; Smith, P.; Williams, C. K. The Technological and Economic Prospects for $\mathrm{CO}_{2}$ Utilization and Removal. Nature 2019, 575, 87-97.

(7) Tackett, B. M.; Gomez, E.; Chen, J. G. Net Reduction of $\mathrm{CO}_{2}$ via Its Thermocatalytic and Electrocatalytic Transformation Reactions in Standard and Hybrid Processes. Nat. Catal. 2019, 2, 381-386.

(8) Porosoff, M. D.; Yan, B.; Chen, J. G. Catalytic Reduction of $\mathrm{CO}_{2}$ by $\mathrm{H}_{2}$ for Synthesis of $\mathrm{CO}$, Methanol and Hydrocarbons: Challenges and Opportunities. Energy Environ. Sci. 2016, 9, 62-73.

(9) Martin, O.; Mondelli, C.; Cervellino, A.; Ferri, D.; CurullaFerré, D.; Pérez-Ramírez, J. Operando Synchrotron X-Ray Powder Diffraction and Modulated-Excitation Infrared Spectroscopy Elucidate the $\mathrm{CO}_{2}$ Promotion on a Commercial Methanol Synthesis Catalyst. Angew. Chemie Int. Ed. 2016, 55, 11031-11036.

(10) Kuld, S.; Conradsen, C.; Moses, P. G.; Chorkendorff, I.; Sehested, J. Quantification of Zinc Atoms in a Surface Alloy on Copper in an Industrial-Type Methanol Synthesis Catalyst. Angew. Chemie Int. Ed. 2014, 53, 5941-5945.

(11) Kuld, S.; Thorhauge, M.; Falsig, H.; Elkjær, C. F.; Helveg, S.; Chorkendorff, I.; Sehested, J. Quantifying the Promotion of $\mathrm{Cu}$ Catalysts by $\mathrm{ZnO}$ for Methanol Synthesis. Science 2016, 352, 969-974.

(12) Behrens, M.; Studt, F.; Kasatkin, I.; Kühl, S.; Hävecker, M.; Abild-Pedersen, F.; Zander, S.; Girgsdies, F.; Kurr, P.; Kniep, B.-L.; Tovar, M.; Fischer, R. W.; Nørskov, J. K.; Schlögl, R. The Active Site of Methanol Synthesis over $\mathrm{Cu} / \mathrm{ZnO} / \mathrm{Al}_{2} \mathrm{O}_{3}$ Industrial Catalysts. Science 2012, 336, 893-897.

(13) Behrens, M. Promoting the Synthesis of Methanol: Understanding the Requirements for an Industrial Catalyst for the Conversion of $\mathrm{CO}_{2}$. Angew. Chemie Int. Ed. 2016, 55, 14906-14908.

(14) Lunkenbein, T.; Schumann, J.; Behrens, M.; Schlögl, R.; Willinger, M. G. Formation of a $\mathrm{ZnO}$ Overlayer in Industrial $\mathrm{Cu} / \mathrm{ZnO} / \mathrm{Al}_{2} \mathrm{O}_{3}$ Catalysts Induced by Strong Metal-Support Interactions. Angew. Chemie Int. Ed. 2015, 54, 4544-4548.

(15) Kattel, S.; Ramírez, P. J.; Chen, J. G.; Rodriguez, J. A.; Liu, P. Active Sites for $\mathrm{CO}_{2}$ Hydrogenation to Methanol on $\mathrm{Cu} / \mathrm{ZnO}$ Catalysts. Science 2017, 355, 1296-1299.

(16) Nakamura, J.; Fujitani, T.; Kuld, S.; Helveg, S.; Chorkendorff, I.; Sehested, J. Comment on "Active Sites for $\mathrm{CO}_{2}$ Hydrogenation to Methanol on $\mathrm{Cu} / \mathrm{ZnO}$ Catalysts". Science 2017, 357, eaan8074.

(17) Kattel, S.; Ramírez, P. J.; Chen, J. G.; Rodriguez, J. A.; Liu, P. Response to Comment on "Active Sites for $\mathrm{CO}_{2}$ Hydrogenation to Methanol on $\mathrm{Cu} / \mathrm{ZnO}$ Catalysts". Science
2017, 357, eaan8210.

(18) Zabilskiy, M.; Sushkevich, V. L.; Palagin, D.; Newton, M. A.; Krumeich, F.; van Bokhoven, J. A. The Unique Interplay between Copper and Zinc during Catalytic Carbon Dioxide Hydrogenation to Methanol. Nat. Commun. 2020, 11, 2409.

(19) Bando, K. K.; Sayama, K.; Kusama, H.; Okabe, K.; Arakawa, H. In-Situ FT-IR Study on $\mathrm{CO}_{2}$ Hydrogenation over $\mathrm{Cu}$ Catalysts Supported on $\mathrm{SiO}_{2}, \mathrm{Al}_{2} \mathrm{O}_{3}$, and $\mathrm{TiO}_{2}$. Appl. Catal. A Gen. 1997, 165, 391-409.

(20) Marwood, M.; Doepper, R.; Renken, A. In-Situ Surface and Gas Phase Analysis for Kinetic Studies under Transient Conditions The Catalytic Hydrogenation of $\mathrm{CO}_{2}$. Appl. Catal. A Gen. 1997, 151, 223-246.

(21) Schild, C.; Wokaun, A.; Baiker, A. On the Mechanism of CO and $\mathrm{CO}_{2}$ Hydrogenation Reactions on Zirconia-Supported Catalysts: A Diffuse Reflectance FTIR Study: Part II. Surface Species on Copper/Zirconia Catalysts: Implications for Methanol Synthesis Selectivity. J. Mol. Catal. 1990, 63, 243254.

(22) Sanchez-Escribano, V.; Larrubia Vargas, M. A.; Finocchio, E.; Busca, G. On the Mechanisms and the Selectivity Determining Steps in Syngas Conversion over Supported Metal Catalysts: An IR Study. Appl. Catal. A Gen. 2007, 316, 68-74.

(23) Nelson, N. C.; Nguyen, M. T.; Glezakou, V. A.; Rousseau, R.; Szanyi, J. Carboxyl Intermediate Formation via an in SituGenerated Metastable Active Site during Water-Gas Shift Catalysis. Nat. Catal. 2019, 2, 916-924.

(24) Richard, A. R.; Fan, M. Low-Pressure Hydrogenation of $\mathrm{CO}_{2}$ to $\mathrm{CH}_{3} \mathrm{OH}$ Using Ni-In-Al/ $/ \mathrm{SiO}_{2}$ Catalyst Synthesized via a Phyllosilicate Precursor. ACS Catal. 2017, 7, 5679-5692.

(25) Rubasinghege, G.; Ogden, S.; Baltrusaitis, J.; Grassian, V. H. Heterogeneous Uptake and Adsorption of Gas-Phase Formic Acid on Oxide and Clay Particle Surfaces: The Roles of Surface Hydroxyl Groups and Adsorbed Water in Formic Acid Adsorption and the Impact of Formic Acid Adsorption on Water Uptake. J. Phys. Chem. A 2013, 117, 11316-11327.

(26) Gotti, A.; Prins, R. Basic Metal Oxides as Cocatalysts for $\mathrm{Cu} / \mathrm{SiO}_{2}$ Catalysts in the Conversion of Synthesis Gas to Methanol. J. Catal. 1998, 178, 511-519.

(27) Nakamura, J.; Nakamura, I.; Uchijima, T.; Watanabe, T.; Fujitani, T. Model Studies of Methanol Synthesis on Copper Catalysts. Stud. Surf. Sci. Catal. 1996, 101, 1389-1399.

(28) van den Berg, M. W. E.; Polarz, S.; Tkachenko, O. P.; Kähler, K.; Muhler, M.; Grünert, W. Dynamical Changes in the Cu$\mathrm{ZnO}_{\mathrm{x}}$ Interaction Observed in a Model Methanol Synthesis Catalyst. Catal. Letters 2009, 128, 49-56.

(29) Waugh, K. C. Methanol Synthesis. Catal. Letters 2012, 142, 1153-1166.

(30) Frost, J. C. Junction Effect Interactions in Methanol Synthesis Catalysts. Nature 1988, 334, 577-580.

(31) Wang, J.; Li, G.; Li, Z.; Tang, C.; Feng, Z.; An, H.; Liu, H.; Liu, T.; Li, C. A Highly Selective and Stable $\mathrm{ZnO}-\mathrm{ZrO}_{2}$ Solid Solution Catalyst for $\mathrm{CO}_{2}$ Hydrogenation to Methanol. Sci. $A d v . \mathbf{2 0 1 7}$, 3, e170129o.

(32) Jia, J.; Qian, C.; Dong, Y.; Li, Y. F.; Wang, H.; Ghoussoub, M.; Butler, K. T.; Walsh, A.; Ozin, G. A. Heterogeneous Catalytic Hydrogenation of $\mathrm{CO}_{2}$ by Metal Oxides: Defect Engineering - Perfecting Imperfection. Chem. Soc. Rev. 2017, 46, 46314644 . 


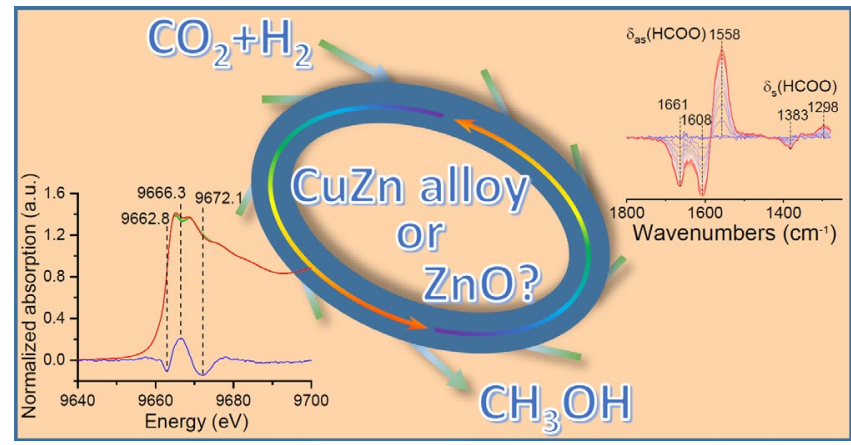

In this operando study, we show that methanol synthesis over Cu/ZnO/FAU catalyst occurs via formate species associated with zinc. Meantime, we came to the conclusion that copper zinc alloy phase is not required to result in the desired reactivity. We attribute the reactive superiority of this catalytic system to the unique interplay between copper and zinc oxide phases. 